\title{
A Stucly of Misalignment Effects of the ANL-APS Electron Linac Focusing System
}

\author{
A. Nassiri. C. Alarrogenes \\ Argonne National Lahoratory \\ 9700 Sonth Cass A veltue \\ Argonne, IL 60439
}

ANL/CP -73122 :

Allstract

We present an analytical treatment of puadrupole misaligmment effects for the Argonne Adranced Plioton Source (APS) 200 - M/c. ${ }^{\circ}$ elect ron linac. The results of numerical molding wilh 'TRANSPOBT [1] are discussed.

\section{INTRODUCTION}

The APS electron limar focusing system consists of three miannetic quadrupole triplets to guide and focus a $1 . \bar{T}$.A hean with final energy of $200 \mathrm{M} / \mathrm{Cl}$ on a positron produclien harget. Aderpuate positron yield requires a small electron bean enittance which means that a beam size of less I. H:an $3 \mathrm{~mm}$ nust be aclieved at the positron production targel [2]. An ofl-centered electron beam at the tungesten target will have at least two effects. First. it will canse positron capture into t.lue pulsed solenoid located immediately after the target to be deteriorated. Second. it will produce wakefields in the dish-loaded accelerating strucfures leading to emititance growth and beam breakup [3]. Jlore, we will only discuss tlie first effect and give a criterion on the bram centroid variation in terms of positron capture into the' pulsed solenoid.

\section{Maginet Displareenent Errons}

The ecination of motion in the transverse plane in the presesuce of a net. displacement error $\delta$, is

$$
\frac{d^{2} \cdot d^{*}}{d s^{2}}+n^{2} d=s^{2} \delta
$$

where $n^{2}=\frac{\mu^{2}}{D^{2}}$ and $\mu$ is the phase anlvance withoul space cliarge and $D$ is the length of the period. If the bean is centered when it. enters a misaligned magnet, then the solution to equation ( 1 ) is obtained as

$$
x(s)=\delta\left[1-\cos k\left(s-s_{i}\right)\right]
$$

and

$$
x^{\prime}(s)=k \delta \sin k\left(s-s_{i}\right) .
$$

At the end of the misaligned magnet. period, the oflsets of the hom cont.roid are given ly-

$$
\alpha \cdot s=\delta[1-\cos n D]
$$

ninl

$$
x_{e j}^{\prime}=n \delta \sin \mathrm{s} D
$$

whice $D=s_{j}-s_{i}$.

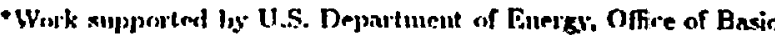

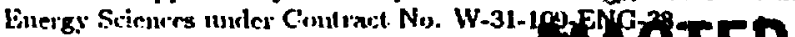

The bean offset proluced is equivalent to an injeclion error for the motion throngh the rest of the focusing system. Thus, equations (4) and (5) can be used as initial conditions to describe the trajectory in the per[ecily aligned section beyond the displaced magnet [4]. The resulting equation is

$$
\begin{array}{r}
\alpha=\delta\left[1-\cos k\left(s_{j}-s_{j}\right)\right] \cos k\left(s-s_{\jmath}\right)+ \\
\kappa \delta \sin k\left(s_{j}-s_{j}\right) \sin k\left(s-s_{\jmath}\right)
\end{array}
$$

or

$$
x=\delta\left[\cos r\left(s-s_{j}\right)-\cos n\left(s-s_{i}\right)\right]
$$

with $k=\frac{\mu l}{D}$ and $s_{e}=\frac{\left(s_{i}+s_{1}\right)}{2}$, equation (j) can be writhen as

$$
x=2 \delta \sin \left(\frac{\mu}{2}\right) \sin \left(\frac{\mu}{D}\right)\left(s-s_{c}\right)
$$

If two adjacent magnets are misaligued by $\delta_{1}$ at position $s_{1}$ and by $\delta_{2}$ al position $s_{2}$. the centroil trajectory downst ream of the magnets can be writlen as

$$
\begin{array}{r}
x=2 \delta_{1} \sin \frac{\mu}{2} \sin \frac{\mu}{D}\left(s-s_{1}\right)+ \\
2 \delta_{2} \sin \frac{\mu}{2} \sin \frac{\mu}{D}\left(s-s_{2}\right)
\end{array}
$$

For $n$ successive misaligned magnets, one lias

$$
x=\sum_{i=1}^{n} 2 \delta_{i} \sin \left(\frac{\mu}{2}\right) \sin \left(\frac{\mu}{D}\right)\left(s-s_{c}\right)
$$

If the misaligument errors are known, one can calculate both the displacement and slope of the bean centroid at the end of the $n$ magnet period. If the misalignment errors are randon. the displacement and slope of the centroid trajectory through a system of $n$ magnets are given as

$$
\begin{array}{r}
x=\sin \left(\frac{\mu}{D}\right) s\left[\sum_{i=1}^{n} 2 \delta_{j} \sin \left(\frac{\mu}{2}\right) \cos \left(\frac{\mu}{D}\right) s_{i}\right]- \\
\cos \left(\frac{\mu}{D}\right) s\left[\sum_{i=1}^{n} 2 \delta_{i} \sin \left(\frac{\mu}{2}\right) \sin \left(\frac{\mu}{D}\right) s_{i}\right]
\end{array}
$$

antl

$$
\begin{array}{r}
x^{\prime}=\frac{\mu}{D} \cos \left(\frac{\mu}{D}\right) s\left[\sum_{i=1}^{\mu} 2 \delta_{i} \sin \left(\frac{\mu}{2}\right) \cos \left(\frac{\mu}{D}\right) s_{i}\right]+ \\
\frac{\mu}{D} \sin \left(\frac{\mu}{D}\right) s\left[\sum_{i=1}^{n} 2 \delta_{i} \sin \left(\frac{\mu}{2}\right) \sin \left(\frac{\mu}{D}\right) s_{i}\right]
\end{array}
$$

The square of the aunplitude of the heam ssrillation after 


\section{DISCLAIMER}

This report was prepared as an acoount of work sponsored by an agency of the United States Government. Neither the Unicod States Government nor any agency thereof, nor any of their employees, makes any warranty. express or implied, or assumes any legal liability or responsibility for the accuracy, completeness, or usefulness of any information, apparatus, product, or process disclosed, or represents that its use would not infringe privately owned rights. Reference herein to any specific commercial product, process, or service by trade mame, Irademark. manufacturer, or otherwise does not necessarily constitute or imply its endorsement, reconmendation, or favoring by the United States Government or any ageacy thereof. The views and opinions of authors expressed herein do not necessarily state or reflect those of the United States Government or any agency thereof. 
passagn through 12 magnets is

$$
\begin{aligned}
r^{2}=x^{2}+\left(\frac{r^{\prime}}{n}\right)^{2}= & {\left[\sum_{i=1}^{n} 2 \delta_{i} \sin \left(\frac{\mu}{2}\right) \cos \left(\frac{\mu}{D}\right) s_{i}\right]^{2}+} \\
& {\left[\sum_{i=1}^{n} 2 \delta_{i} \sin \left(\frac{\mu}{2}\right) \sin \left(\frac{\mu}{D}\right) s_{i}\right]^{2} }
\end{aligned}
$$

After simplifying. this ran be: written as

$$
d^{2}=4 \sin ^{2} \frac{\mu}{2}\left[\sum_{p=1}^{n} \delta_{p}^{2}+\sum_{q=1}^{n} \sum_{p \neq \varphi}^{n} \delta_{p} \delta_{q} \cos \frac{\mu}{D}\left(s_{p}-s_{q}\right)\right]
$$

lor a se of $n$ inskependent. jolentically distributed random crors.s. the aremore of the distribution for each magnel is

$$
\left\langle\delta_{i}\right\rangle=0 \quad \text { for } \mathrm{i}=1, \ldots, \mathrm{n}
$$

and

$$
\left\langle\delta_{i}^{2}\right\rangle=\left\langle\delta^{2}\right\rangle \text { for } \mathrm{i}=1, \ldots, \mathrm{n}
$$

Each possible sel of the $n$ magnets will give a different. value for d. Taking the average value over all sets gives

$$
<\delta_{p} \delta_{q}>= \begin{cases}0 & p \neq 0 \\ \delta^{2} & p=q\end{cases}
$$

so

$$
\left.\left\langle d^{2}\right\rangle=4 \sin ^{2} \frac{\mu^{\mu}}{2} n<\delta^{2}\right\rangle
$$

or the rms value is

$$
i_{r m s}=2 \delta_{r m s} \sqrt{n} \sin \left(\frac{\mu}{2}\right)
$$

with

$$
\left.\delta_{r m s}=\left(<\delta^{2}\right\rangle\right)^{2}
$$

\section{Migine't Rotation ERrors}

If lhere are randon errors in rotation of each magnet. ahout the axis of the for using channel, there will be transverse amplitude growth. 'The cliange in transverse aunplilucle (say in $x, x^{\prime}$ phase space) is calculated by considering

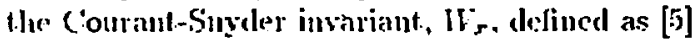

$$
\frac{11}{13}=7_{x} x^{2}+211_{x} \cdot x^{\prime}+\beta_{x} x^{\prime 2}
$$

'Tlir clange in $\mathbb{I}^{\circ}$, for $\lambda$ successive magnets with rotalion error $\epsilon_{\lambda}$. is [i]

$$
\delta H_{x} \cong \sum_{\lambda=1}^{n} 2\left(\beta_{\gamma}\right)\left(\alpha_{x}^{\lambda} x_{\lambda}+\beta_{s}^{\lambda} x_{\lambda}^{\prime}\right) \sigma_{\lambda} c_{\lambda} \epsilon_{\lambda} y_{\lambda}
$$

The change in radial anplitude is a maximum for the case $A_{x}=A_{y}=\frac{d}{\sqrt{2}}$, where $\beta_{y} A_{x, y}^{2}=\beta_{m a x} W_{x, y}$. Expressing x. $x^{\prime}, y, y^{\prime}$ in Icrms of the amplitude and plase of the? I ransverse oscillations, one obtains [5]

$$
\frac{\delta d_{n}}{d_{n}} \cong \frac{1}{2} \sum_{\lambda=1}^{n} \kappa_{\lambda} C_{\lambda} C_{\lambda}\left(\xi_{x}{ }^{\lambda} \beta_{y}{ }^{\lambda}\right)^{\frac{1}{2}} \sin \left(\hat{\phi}_{o}+2 \lambda \mu\right)
$$

where $\phi_{0}$ is the sum of the $a$ and $y$ starling plases. $\mu$ is the phase adrance of either oscillation, and the subscript or superscript $\lambda$ refers to the value at the $\lambda$ magnet. There is a value of $\phi_{a}$ for which equation (19) is maximum. For this value and with the assumption of uncorrelated errors $c_{\lambda}$. will rus valne $c$, one has [5]

$$
\left(\frac{\delta d_{n}}{d_{n}}\right)_{\max } \cong \frac{\epsilon}{2}\left[\sum_{\lambda=1}^{n} \frac{\beta_{x}^{\lambda} \beta_{y}^{\lambda}}{\sigma_{\lambda}^{2}} \sigma_{\lambda}^{\frac{1}{2}}\right]^{\frac{1}{2}}
$$

\section{NUMIERICAL SINULATIONS}

M isalignments of the electron linac focusing triplets were studied using 'lRANSI'OK'I [1]. Quadrupole triplets wrre randounly misaligued (assuming a (Gaussian dist ribution) will $\sigma_{x . y}=0.3 \mathrm{~mm}$ and $\sigma_{x^{\prime}, y^{\prime}}=2.0 \mathrm{mrad}$. Three cases were consiclered: (1) lateral displacement. (2) rotattion around the transterse axes, and (3) quadrupole liceld gradlent errors.

Ten stat istically independent. sets of misaligneel triplets were produced for eaclu type of misaliguneent. The prerfurbed trajectories were then calculated using TRANSl'ORT [1]. 'The runs deviations of the beam centroid along the electron linac were calculated. Figures 1 ancl 2 illustrate the beam centroid fluctuation due to displacement. and rotation errors respectively.

\section{SUMMARY AND DISC'USSION}

'T lie capt ure of the positrons into the pulsed solenoid located after the positron production larget depends on low well the electron beam is centered on that target. If the electron beam spot is displaced from the center of the targel. by $\delta \rho$, in order to liave a $90 \%$ caplure, $\delta \rho$ slionlul be $\sim 0.1 d(d=$ beam diameter $)$. This crilerion sets the limits on the misalignment. tolerances. Exuation (16) slows that the standard deviation is proportional to mus error and grows as $n^{\frac{1}{2}}$. Figures 1 and 2 indicate this relotion. The simulations also slow that the rantom guadrupole displacenent errors have st rouger elfects than the rotation errors. This is lo be expected when the cuaclrupoles are arranged as stmmetric tripleo. 'The magnelic ficld gradichl variation on entadrupoles is specified to he better than 0.1\%. Simmlations indicate that. no significant. hean degradation uccurs at this colerauce level. Sinulalions indicale that a parallel displaces:ent error tolerance of $0.3 \mathrm{~mm}$ and an axial rotation etror tolerance of 2.0 mrad are acceptable (see Figures 3 and 4 ). 


\section{AC'RNOWLEDGEMISN]}

A. Nassiri has greally bonefited from discussion with Ed ('rosbije on the perlubbalion eflects in hean focusing sysmons. Thanks to Rahinder lionl for useful conversations.

\section{RF-ERENCES}

[1] Daviul (. Carey, "Thirsl Onder TRANSPORT with MAl) Gnput."ThI-15.16. FNAl, 1988.

[2] A. Nassiri. W. Misolowsli, and (i. Marrogenus. "The

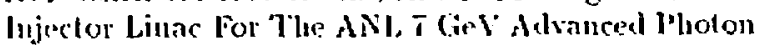
Source," in Procedings of the 1990 Lincar Acreicrator Conforence, p. 611. Sirplomber 10!0.

[3] 1R. D. Ruth, "The Next Linear collieler." SLAC" Pl!13 5106. SLAC!. Fomary 1994.

[1] A. Reizer, "Tlienry duel Design or Charged Particle? Bean," (Iniversity or Mary!and. 198!),

[5] 1R. (Alucksteru. "Inusverse Bean Quality In linacs." in Proccrdings of Sisth sutcrmational Conference On High Encrgy Accolemtors, p.15i, 1916i.

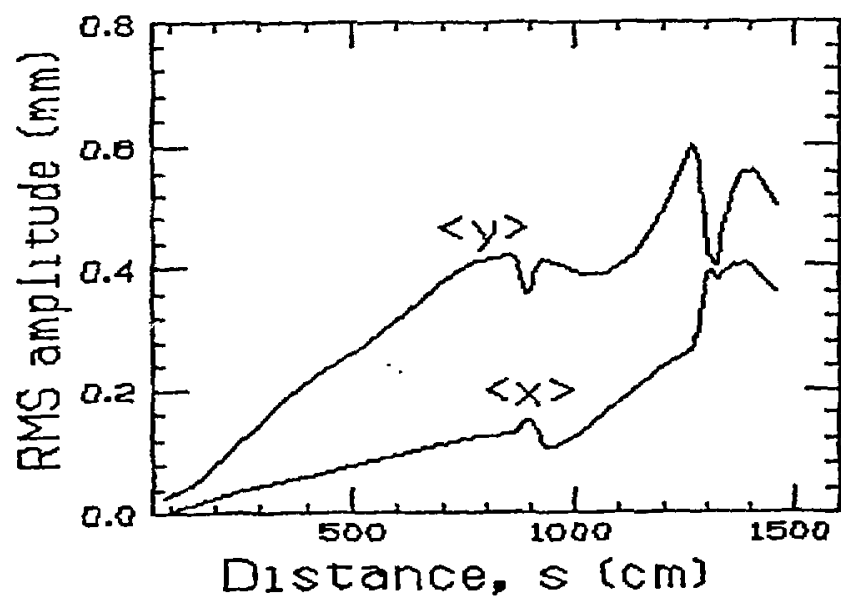

Figure 1. Fluctuation of beam centroid due to random displacement error

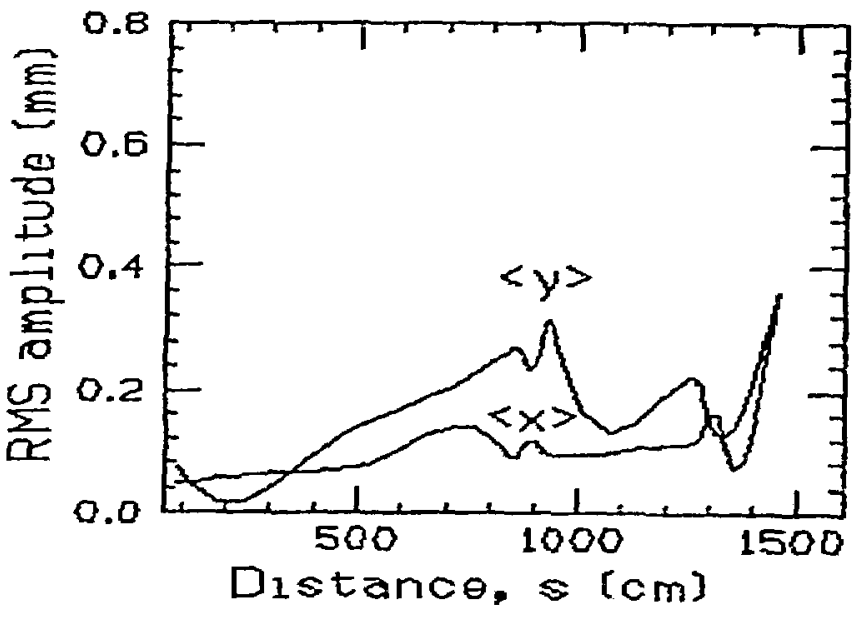

Figure 2. Fluctuation of beam rentroil lue fo randoma rotational error

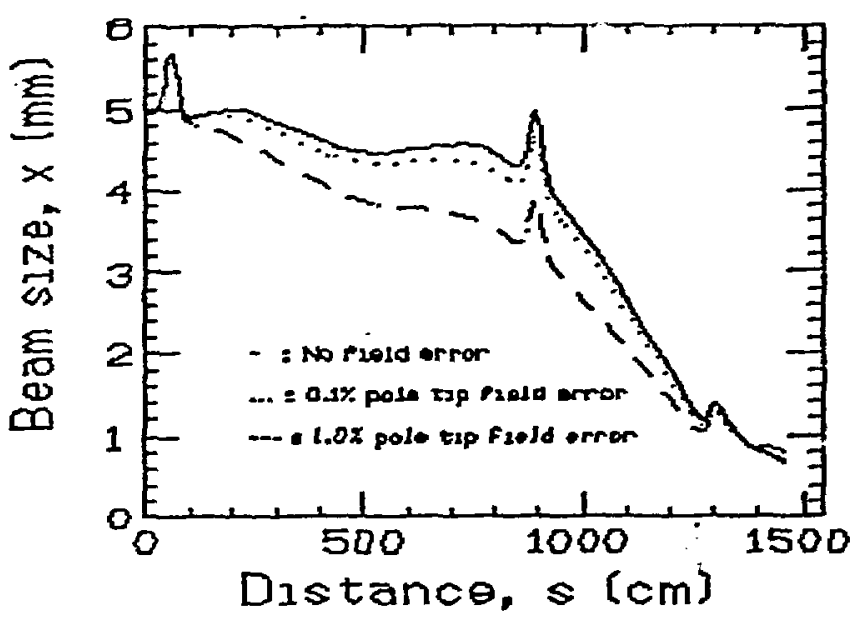

Figure 3. Beam size $(x)$ profile variation due to field gradient error

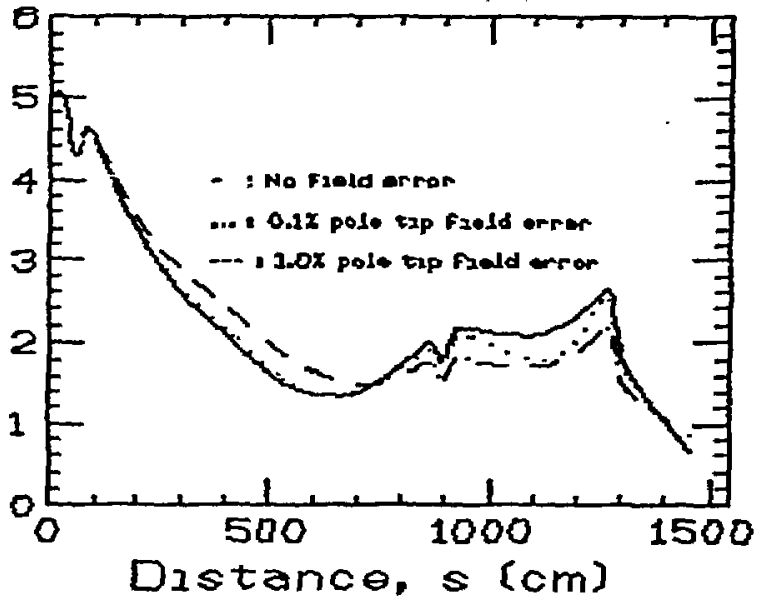

rigure 4. Beam size (y) profile varialion due to field gradient error 